Final Submission to Politics

Claire Dunlop ${ }^{1}$ (University Of Strathclyde)

\title{
Epistemic Communities: A Reply to Toke
}

In his recent article in Politics David Toke provides a critical review of Peter Haas's ${ }^{2}$ epistemic communities approach. Toke's critique is that Haas awards too much influence to experts in these communities in the shaping of decision-makers' interests and perceptions, at the expense of interest groups and social movements ${ }^{3}$. In this reply it will be argued that, while Toke's recognition of epistemic communities' problematic relationship with other groups in general is perceptive, his specific contention of an implied normative superiority, of either them or their knowledge, rests upon a misreading of the approach's philosophical origins and influences. It is not in dispute that Haas has failed to produce an approach capable of accommodating the multiplicity of actors, epistemic and non-epistemic, who at various junctures influence the norms of decision-makers and, crucially, of one another. Rather, what is challenged is the idea that this omission is due to the pursuit of a positivist agenda and an attempt to 'sell' epistemic communities as the most important actors in technical policy areas.

This response pursues two main arguments. The first maintains that Toke's identification of a positivist grammar running through Haas's approach is overstated. Neither the philosophical discussions in Haas's introduction (20-34), nor the case study evidence contained in the 1992 Epistemic Communities Special Edition of International Organisation provide sustenance for the critique. The second strand of the response examines the role of interest groups and their interactions with epistemic communities. It is argued that the inability of Haas to provide a convincing conceptualisation of the connections between epistemic communities and wider groups stems from his initial construction of the concept and its empirical undernourishment, rather than any deeprooted positivist precept. 


\section{Section 1: Distinguishing epistemic communities from the rest}

Toke asserts that Haas's epistemic communities approach reproduces a positivist ideology, one consequence of which is a marginalisation of environmental groups in two of the International Organisation case studies (1999: 97). Toke maintains that epistemic communities view their own advice as the ultimate truth which they are uniquely endowed to impart to governments. Thus for him, Haas aims to convince scholars that: 'Scientists can allow the truth about the real world to shine forth in the end' (1999: 98).

The superiority which Toke believes is conferred upon epistemic communities originates in the shared causal beliefs systems and consensual knowledge they possess (Haas, 1992a: 18). From this view, environmentalists, and more broadly all nonepistemic actors, are deliberately relegated to the task of amplifying the voices of expert communities, having no 'truth' of their own to purvey.

However, this specification of difference does not automatically imply that Haas attempts to advance epistemic communities normatively. It may just as easily intimate his concern to record the view that expert groups are not a brand of specialised interest groups with non-material aims (1992a: 19). For Haas, epistemic communities possess a unique blend of characteristics, two of which are exclusive to knowledge communities acting in accordance with an internally settled paradigm. In his introduction, Haas lays out a four-step definition, which states:

‘...Although an epistemic community may consist of professionals from a variety of disciplines and backgrounds, they have (1) a shared set of normative and principled beliefs, which provide a value-based rationale for the social action of community members; (2) shared causal beliefs, which are derived from 
their analysis of practices leading or contributing to a central set of problems in their domain and which then serve as the basis for elucidating the multiple linkages between possible policy actions and desired outcomes; (3) shared notions of validity - that is, intersubjective, internally-defined criteria for weighing and validating knowledge in the domain of their expertise; and (4) a common policy enterprise - that is, a set of common practices associated with a set of problems to which their professional competence is directed, presumably out of the conviction that human welfare will be enhanced as a consequence' (Haas, 1992a: 3).

The crucial claim to distinctiveness rests on elements 2 and 3. Haas consistently implies the non-negotiable nature of these two elements - without them, the epistemic community ceases to function as an authoritative voice of advice in state decisionmaking. For example, in the event of a serious challenge to the causal 'world view' of the community (2) which could not be settled internally (3), Haas is firm that the community would withhold policy advice: 'Unlike an interest group, if confronted with anomalous data, they would retract their advice or suspend judgement' (1990: 55).

Haas's listing of the defining characteristics of epistemic communities need not be taken as any assertion of moral superiority on their part, rather it conveys a degree of definitional rigidity in epistemic communities which differentiates them from interest groups. This distinction is apparent in the fact that the claims to influence by interest groups or social movements would not be undermined decisively by the discovery of technical anomalies which are irreconcilable with the received wisdom.

Another line of argument advanced by Toke concerns the apparent claim by Haas that epistemic communities alone are best placed to discern and articulate for governments the complex linkages and inter-relationships which are inherent in technical policy 
problems (1999: 98). This assertion represents a considerable stretching of what Haas argues, which is:

'Without the help of experts, they [governments] risk making choices that not only ignore the interlinkages with other issues, but also highly discount the uncertain future' (1992a: 13).

Rather than awarding a monopolistic position to epistemic communities, Haas appears to be flagging up a gap in the conventional International Relations literature and macro theories which he is aiming to fill. His concern is to identify the role of experts in framing collective debate and the fostering of international co-operation in conditions and policy areas characterised by knowledge deficits and uncertainty. Even if Toke's interpretation of this role is accepted, there must still be a strong case for the privileging of those experts at the front line of knowledge production and dissemination. Thus Haas appears to be underlining the rationale behind his approach - to move theorists beyond the existing structure/agency binary offered by the dominant theoretical approaches, rather than attempting to establish a hegemonic position for epistemic communities over environmental groups.

\section{Unfettered positivism?}

Although not explicitly delineated as such, Toke's charge of positivism appears to be two-fold, with one argument the tenant of the other. At a fundamental level, Toke views the concept's emphasis on knowledge as cloaked in the 'positivist ideology in society at large' (Toke, 1999: 97). What exactly he means by this is not clear. It does not appear to be the centrality of knowledge per se to which Toke objects. In citing Ulrich Beck's assertion that many different knowledge types co-exist (1999: 101), from his 'demonopolization of science' argument (Beck, 1992: 163-7), Toke concurs that knowledge is important in technical policy areas. Therefore it has been deduced that what Toke finds exclusionary is the particular nature of epistemic communities' 
knowledge and the manner in which it is created. This then leads to his second argument that other groups and their knowledge types are undermined by Haas' thesis.

Nowhere in Toke's critique does he pin Haas down as an empiricist. In essence, his challenge is restricted to attacking Haas for aiming to be all things to all people by hiding his thesis behind a tag of 'limited constructivism' (1992a: 23). What Haas actually means by this is best understood with reference to an epistemic community's 'internal truth tests' which facilitate his 'consensual theory of truth'. Through these tests (located in element 3 of his definition), which come in such forms as debate, re-testing and peer review, knowledge is validated and agreed. As noted above, this consensus is the linchpin of an epistemic community's claim to authority. However, it is not a synonym for ultimate truth. Therefore, while the method of knowledge validation through cause and effect principles - could be construed as positivistic in style, Haas clearly does not aim to convey any sense of 'correct belief'. Rather, the knowledge consensus represents a 'temporally bounded notion of truth' (1992a: 23, added emphasis). Over time, this particular 'truth' will evolve, be challenged and altered or debunked and replaced as new discoveries dictate.

Haas then does not conceptualise reality in positivistic terms or view knowledge as set in stone, rather he believes: 'The world and our representation of it are not isomorphic ... reality is mediated by prior assumptions, expectation and experience' (1992a: 21). Thus, while the term 'limited constructivism' does appear nebulous, the clear references to interpretative visions of reality as socially-constructed renders Haas in step with social constructivists like Liberatore (see Toke, 1999: 101). Furthermore, the fact that the positivist role of philosophy merits only a passing glance in Haas's discussion serves, at the very least, as prima facie evidence that his thesis is not rooted in positivism. 
The central argument against the charge of a positivist prejudice can be found in the concepts of consensual knowledge and intersubjective truth tests. Haas's focus on these reveals the imprint of Thomas Kuhn's The Structure of Scientific Revolutions (1962). Indeed, Haas is explicit in his International Organisation introduction (1992a: 3, footnote 4) about the influence of Kuhn's critique of positivism as science's 'orthodox model'. For Kuhn, the most dominant feature of scientific development is its subculture - the scientific community. He argues that theories are crafted not only upon the facts at a scientist's disposal, but that they also rest upon the tradition in which they participate. Thus Kuhn's community of knowers is constituted both socially and historically. He rejects the idea that appeals can be made to empirical evidence as some final arbiter - what counts is the paradigm: the community's world view.

The similarities between Kuhn's conceptualisation of paradigms and Haas' notion of epistemic communities and consensual knowledge is undeniable and is a feature noted by other commentators, for example Guy Peters (1996: 72). There is, therefore, an identifiable intellectual 'pre-history' and epistemic community structure which embodies post-positivist principles. Indeed, Toke himself notes that the creation of knowledge consensus is not a positivist hallmark, and given that this is a central component of the thesis, any argument against Haas ploughing a post-positivist furrow would have to be qualified more strenuously.

Toke raises the expectation that, in following Haas, the outputs of epistemic communities would reflect a 'value-free conclusion' (1999: 101). However, Haas sees the type of information which an epistemic community is called upon to supply as being, 'Neither guesses nor 'raw' data: it is the product of human interpretations of social and physical phenomena' (1992a: 4). Indeed, Haas's own case study on CFCs, cited by Toke, provides a prime example of the centrality of agreed knowledge, rather than proven truths. In this case study, the atmospheric epistemic community bound 
itself to the 'Rowland-Molina' hypothesis which focused upon CFC's chlorine origins, linking them to the depletion process. Even though this had not been confirmed, the hypothesis was 'sold' to the decision-makers and to the public because the consensus was firm. In addition, it was emphasised that if the US waited for depletion proof, the interim damage could be irreversible (1992c: 200). This highlights that, for Haas, the motivations of epistemic communities derive from shared causal and principled beliefs, and their political empowerment comes from the ability to translate consensual authoritative knowledge into policy. It is in this sense that epistemic communities are bearers of $a$ truth.

However, despite the consistency with which post-positivism is implied in this approach, Haas - rather like $\mathrm{Kuhn}^{4}$ - is undeniably reluctant to openly nail these colours to his mast. Indeed, in their conclusion, Adler and Haas side-step making a categorical statement concerning the philosophical commitment of the approach. Rather they prefer to focus upon the approach's primary goal - to bridge the positivist-interpretative gap inherent in international relations orthodoxies (1992: 370). However, the evidence from his expositions and all extrapolations of the concept only point in one direction towards a post-positivist pole ${ }^{5}$.

\section{Section 2: The 'other groups' problems}

While rejecting Toke's claims of positivist ideology resulting in a normative bias, the critique he presents does prompt important wider questions about the manifest inability of the thesis to acknowledge and explain the interactions of epistemic communities with other actors in contemporary policy arenas. Fundamental to the approach's failure to engage with the real world of politics and interest group bargaining is a lack of critical empirical testing. Despite a growing body of case studies using and alluding to the approach (most recently, Verdun, 1999) ${ }^{6}$, the framework remains an inchoate one. Karen Litfin's Ozone Discourses (1994) presents a rare (and successful) attempt to 
rigorously examine the concept's utility in relation to the 'Montreal Protocol on Substances that Deplete the Ozone Layer'. A plausible explanation of why the type of pressure necessary for conceptual refinement has not been exerted upon Haas' framework is offered by Wright (1997). Wright correctly points highlights the basic methodological complexity of operationalising such a micro-level approach where he says,

'Actually identifying these communities can ... be a very difficult process' (1997: 11).

It seems likely that the practical obstacles entailed in the approach, such as identifying, locating and gaining access to those believed to be members of any epistemic community (this is before any attempt can be made to discern their importance), may have frustrated some scholars attempts to use and test the thesis effectively, if at all ${ }^{7}$.

And so the approach as it stood in the 1992 Special Edition remains largely the same today. As a result, contradictions and omissions in the epistemic communities idea have remained hidden, and require exploration. In the remainder of the article the 'other groups' problem apparent in Haas' work is outlined and a conceptual reconstruction, as a remedy, is sketched.

On the issue of other groups, Haas is, at best, indirect. Indeed, actual acknowledgment of their existence is made only implicitly. His case studies mention the input of other actors, though not their relationship to the epistemic communities, and make only oblique references to unspecified 'rivals' (1990: 57; 1992b: 44). Haas is similarly coy about the degree of political power which an epistemic community can exercise. It is this uncertainty concerning epistemic communities' political motivations which contributes most to its 'other groups' problem. Haas portrays the epistemic communities as 'politically empowered' by their consensual knowledge (1992b: 41). However, the approach's stress on co-operation ensures that the degree of power and the impact of the 
epistemic communities' main commodity in the policy debate is never systematically considered. As Litfin points out, 'Epistemic communities approaches downplay - almost to the point of neglect - the ways in which scientific information simply rationalises or reinforces existing political conflicts' (1994: 12). Thus it may be that the much vaunted 'consensual knowledge' may overstate the influence these expert enclaves alone can have.

Haas's uncertainty about the relationship between epistemic communities and political reality is a theme also taken up by James Sebenius. His critique in the International Organisation Special Edition remains one of the most extensive and penetrating to date. Sebenius's contention is that the approach ignores the often conflictual nature of the arenas in which expert actors operate - contexts in which being 'apolitical' (yet 'politically empowered') seems unfeasible. Rather, an epistemic community's influence emanates from bargaining with other actors in an attempt to convert their "natural coalition' of believers into a 'winning coalition', pushing forward a shared policy enterprise (characteristic 4 of an epistemic community) (Sebenius, 1992: 325). Therefore, epistemic communities have to be politically proactive players to convey their message, interacting with a multiplicity of other actors where it is to be expected that influence is variable and contingent as wider strategic games are played out. In such a scenario, the full potential of consensual knowledge may only be realised through the involvement of other, more politically astute, groups with the epistemic community.

Sebenius's critique demands an opening-up of the approach to expose epistemic communities to greater competition and conflict, as well as flagging up the political potential of their shared policy project. This idea of an epistemic community aiming to be a 'winning coalition' could actually explain some of the anomalies highlighted by Toke (1999: 99) in M.J. Peterson's whaling management case study (1992: 147-86). It is possible that the 'political eclipse' (Peterson, 1992: 154) which engulfed cetologists 
in the 1970s was deliberately turned into a strategic plus when experts transferred to form such a 'winning coalition' with environmentalists, whose conceptualisation was in political ascendancy at that time.

As it stands, the framework is unable to accommodate the bargaining which would be entailed in coalition building between epistemic communities and other groups.

Alterations to the approach's construction are required which can accept the fluctuating nature of all actors' influence in the policy process, and more widely, explain why and under what conditions epistemic communities will 'show up in outcomes' (Sebenius, 1992: 326). This increased level of explanatory power may only be secured if the four characteristics of the epistemic community itself are problematised and their importance relative to each other elucidated. The problem is that, unlike Sabatier's 'advocacy coalition framework' approach $(1988 ; 1998)$, Haas does not explicitly single out any one feature as representing the 'deep core' of the community's belief system. While he does note the importance of elements 2 and 3 in distinguishing epistemic communities from materially-based groups, he fails to discuss the implications of their apparent firstamong-equals status for the other two elements. Furthermore, he does not appear to countenance circumstances where one of these other 'bridesmaid features' could dominate the others. In terms of interaction with other groups and coalition formation, the epistemic communities' shared policy project would be central, as Sebenius suggests ${ }^{8}$.

On this matter, Haas only intimates that, over time and with political exposure, changes could occur in the epistemic community's belief system - then affecting the policy paradigm of the community. He and Adler state that: 
'As epistemic communities consolidate and expand their political and bureaucratic influence internationally, additional ideas may be incorporated into the core community beliefs' (1992: 374).

However the inverse of this is never tackled. Examined the other way round, the susceptibility of a community's policy project to change, without disturbing its core belief system, would be key in determining a community's propensity toward coalition building in a given policy area.

Through more 'theory-infirming' empirical studies (Lijphart, 1971), hypotheses concerning the relative weights of each factor in particular conditions - such as periods of political uncertainty or negative media attention - can be constructed and tested. This would facilitate the degree of sophistication necessary if epistemic communities' interaction and dependency on other groups are to be explained. Assuming greater elasticity in the structure of an epistemic community and borrowing ideas from the advocacy coalition framework would lead to an explicit acknowledgment not only that beliefs matter for the work of the community or subsystem, but a recognition that, in certain situations, some may matter more than others. This would enable the approach to acknowledge openly the reality of competition which often exists between epistemic communities and interest groups. In addition, such refinement would ensure meaningful examination of the multiple knowledge 'truths' at large in one policy area and why certain 'truths' prevail under particular conditions. Thus the existence of many realities is not precluded by the philosophical features of the concept, but rather, these realities cannot be fully understood without some slack being worked into the approach's features. 


\section{Bibliography}

Adler, E. and P.M. Haas (1992) 'Conclusion: Epistemic Communities, World Order and the Creation of a reflective research program' in International Organisation 46 (1): $367-390$.

Beck, U. (1992) Risk Society: Towards a New Modernity (London: Sage)

Fry, M. G. and Hochstein, M. (1993) 'Epistemic communities - Intelligence Studies and International Relations' in Intelligence and National Security 8 (3): 14-28.

Haas, E.B. (1990) When Knowledge is Power (Berkeley: University of California Press)

Haas, Peter M. (1990) Saving the Mediterranean - the politics of international environmental co-operation (New York: Columbia University Press)

Haas, Peter M. (1992a) 'Introduction: epistemic communities and international policy co-ordination' in International Organization 46 (1): 1-36

Haas, Peter M. (1992b) 'Obtaining International environmental protection through epistemic consensus' in Rowlands I.H. and M. Greene (eds) Global Environmental change and international relations (Basingstoke: Macmillan)

Haas, Peter M. (1992c) 'Banning Chloroflurorcarbons: Epistemic Community efforts to protect stratospheric ozone' in International Organization 46 (1): 187-224.

Haas, Peter M., R.O. Keohane and M.A. Levy (eds) (1993) Institutions for the Earth (London: The MIT Press)

Haas, Peter M. (ed) (1997) Knowledge, Power and International Policy Co-ordination (Columbia: University of South Carolina Press)

Haas, Peter M. (1999) 'Social Constructivism and the Evolution of Multilateral Governance' in Hart, J. and Prakash, A. (eds) Globalization and Governance (London: Routledge) 
Haas, Peter. M. and Haas, E. B. (1995) 'Learning to Learn: improving international governance' in Global Governance 1 (3): 255-284.

Hjorth, R. (1994) 'Baltic Sea environmental co-operation. The role of epistemic communities and the politics of regime change' in Co-operation and conflict 29 (1): 11-31.

Kuhn, T. (1962) Structure of Scientific Revolutions (Chicago: Chicago University Press)

Kuhn, T. (1977) The Essential Tension (Chicago: Chicago University Press)

Lijphart, A. (1971) 'Comparative Politics and the Comparative Method' in American Political Science Review 65 (3): 652-693.

Litfin, K.T. (1994) Ozone Discourses: Science and Politics in Global Environmental Cooperation (New York: Columbia University Press)

Peters, B.G. (1996) 'Agenda-setting in the European Union' in Richardson, J.J. (ed) European Union: Power and Policy-Making (London: Routledge)

Peterson, M.J. (1992) 'Whalers, Cetologists, Environmentalists and the International Management of Whaling' in International Organisation 46 (1): 147-186.

Richardson, J. J. (1994) 'EU water policy: Uncertain agendas, shifting networks and complex coalitions' in Environmental Politics 3 (4): 139-168.

Sabatier, P.A. (1988) 'An advocacy coalition framework of policy change and the role of policy oriented learning therein' in Policy Sciences 21: 129-168.

Sabatier, P.A. (1998) 'The advocacy coalition framework: revisions and relevance for Europe' in Journal of European Public Policy 5 (1): 98-130.

Sebenius, J.K. (1992) 'Challenging Conventional Explanations of International Cooperation: Negotiation Analysis and the case of epistemic communities' in International Organisation 46 (1): 323-365. 
Shapere, D. (1964) 'The Structure of Scientific Revolutions' in The Philosophical Review 73 (July): 389-340.

Thomas, C. W. (1997) 'Public management as interagency co-operation: testing the epistemic community theory at the domestic level' in Journal of Public Administration Research and Theory 7 (2): 221-246.

Toke, D. (1999) 'Epistemic Communities and Environmental Groups' in Politics 19 (2): 97-102.

Verdun, A. (1999) 'The role of the Delors Committee and EMU' in Journal of European Public Policy 6 (3): 308-329.

Wright, K. (1997) 'Knowledge and expertise in European conventional arms control negotiations: an epistemic community?', The European Policy Process Occasional Papers, No. 41 (Department of Government, University of Essex) 
1 Thanks to David Judge and two anonymous referees for their perceptive comments on earlier drafts of this article. The usual disclaimer applies.

$2 \quad$ It should be made explicit that the epistemic community thesis examined by Toke is that of Peter M. Haas rather than Ernst B. Haas who also developed this concept, most notably in When Knowledge is Power (1990).

3 Following P.M. Haas (1992a: 16-20), Toke deals with these two group types simultaneously, any distinction between them being inconsequential in this discussion.

$4 \quad$ See Shapere (1964) and Kuhn (1977) for more on this philosophical tension in Kuhn's work. 5 This philosophical commitment is further borne out in Haas's subsequent works exploring international policy co-ordination and learning through the application of consensual knowledge. In these Haas pursues an explicitly social constructivist research agenda (see 1995 with E.B. Haas \& 1999).

The epistemic community concept has been invoked in many empirical studies - such as the case studies of the International Organisation Special Edition of 1992 and subsequently by Fry and Hochstein (1993); Hjorth (1994); Richardson (1994) and Thomas (1997) among others. However the author remains sceptical that these prove the concept's use in its current form.

$7 \quad$ I am grateful to one of my anonymous referees for suggesting this point to me.

8 Haas also fails to address circumstances where epistemic communities may be effectively 'hired' by administrations to add credibility to a pre-determined policy preference. In such cases, the epistemic communities would be told the end to which means were to be tailored. A good example of this is provided in Verdun's study of the EMU Delors Committee (1999: 308-329). 